\title{
Study of caesarean section at tertiary care centre: a retrospective study
}

\author{
Varsha Kose, Kumari Sadhvi*
}

Department of Obstetrics and Gynecology, N. K. P. Salve Institute of Medical Sciences and Research Centre and Lata Mangeshkar Hospital, Hingna, Nagpur, Maharashtra, India

Received: 09 March 2020

Accepted: 01 April 2020

*Correspondence:

Dr. Kumari Sadhvi,

E-mail: dr.sadhvisantosh@gmail.com

Copyright: () the author(s), publisher and licensee Medip Academy. This is an open-access article distributed under the terms of the Creative Commons Attribution Non-Commercial License, which permits unrestricted non-commercial use, distribution, and reproduction in any medium, provided the original work is properly cited.

\begin{abstract}
Background: Caesarean section (C-section) is one of the most widely performed surgical procedure in obstetrics worldwide. The WHO guidelines revised in 1994 states that the proportion of C-section birth should range between 5$15 \%$ but both in developed and developing countries $\mathrm{C}$-section rate is on the rise. This study was conducted to analyse the frequency and indications for $\mathrm{C}$-section and associated maternal morbidity and mortality.

Methods: This retrospective study was conducted over a period from January 2018 to May 2019 at the department of obstetrics and gynecology, NKP Salve Institute of Medical Sciences and Research Centre and Lata Mangeshkar Hospital, Hingna, Nagpur, Maharashtra, India. Data of patients who delivered by C-section in our hospital during the defined study period were studied and statistically analysed according to various parameters namely, the frequency of caesarean section, its indications, age, parity and gestational age of the patient.

Results: The total number of women delivered over the study period were 2811. Out of which C-sections were done in 1461 women (51.97\%). Previous C-section was the leading indication in $35.72 \%$ women followed by fetal distress $14.09 \%$, failure of induction $12.93 \%$, arrest of labour $7.93 \%$, PIH $7.18 \%$, oligo/IUGR $6.50 \%$, breech $4.44 \%$, refusal of vaginal birth $4.24 \%$, CPD $1.71 \%$, bad obstetrics history (BOH) $1.43 \%$, malpresentation $1.30 \%$, prematurity $1.23 \%$, and multifetal gestation in $1.09 \%$ women. Two women had classical C-section 0.07. 14.09\% women had various complications. There was no maternal mortality.

Conclusions: A high rate of caesarean deliveries was observed. Individualization of the indication and careful evaluation, following standardized guidelines can help us to limit C-section. Audit and feedback are the best way to judge clinical practice and to reduce the frequency of caesarean section in any tertiary setup.
\end{abstract}

Keywords: Foetal distress, Lower segment caesarean section, Previous caesarean section

\section{INTRODUCTION}

Caesarean section is one of the most widely performed surgical procedures in obstetrics worldwide. It was mainly evolved as a lifesaving procedure for mother and foetus during the difficult delivery.

The WHO published guidelines regarding C-section rates in 1985 which was revised in 1994. The guidelines published in 1997 by UNICEF, WHO, and UNFPA states that proportion of caesarean birth should range between 5 to $15 \% .^{1-3}$ According to a research article, the global average $\mathrm{C}$-section rate increased from $6.7 \%$ to $19.1 \%$ between 1990 and $2014 .^{4}$

According to the federation of obstetric and gynaecological societies of India" the hallmark of labour management in the $21^{\text {st }}$ century should be individualized care for the labouring woman with the expectation of a successful and safe vaginal delivery, together with the ability to intervene with a caesarean delivery, if needed, to prevent morbidity and mortality., 
But both in developed and developing countries Csection rate is on the raise. This study was conducted to Analyse the frequency and indications for C-section and associated maternal morbidity and mortality.

There is progressive increase in caesarean deliveries across the world; in developed as well developing countries. This increase in $\mathrm{C}$-section rate has become a major public health issue, because. , $^{6,7}$

- It is a burden on health system and imposes stress on families.

- It had been observed that caesarean deliveries are associated with increased risk of maternal and Perinatal morbidity as compared to vaginal deliveries even in low risk cases.

- The rapid increase in caesarean birth rates without clear evidence of concomitant decreases in maternal or neonatal morbidity or mortality raises significant concern that caesarean delivery is overused.

At present there is no strictly defined protocols for the indication of C-section in our country. So, at present the decision for LSCS is mostly individualised and depends on the obstetrician taking care of the parturient WHO advises that $\mathrm{C}$-section rates should not be more than $15 \% .^{8}$

India's rising rate of caesarean births is a cause for concern and signals the need for strategies to deal with it. Adverse outcomes of caesarean births include high risk of maternal and neonatal death, various maternal morbidities including infections, need for blood transfusion, neonatal morbidities related to iatrogenic prematurity, and potential complications in subsequent pregnancies. $^{9}$

The present study was an effort to determine the frequency of $\mathrm{C}$-section and evaluate the indications in the department of obstetrics and gynaecology, N. K. P. Salve Institute of Medical Sciences and Research Centre and Lata Mangeshkar Hospital, Hingna, Nagpur, Maharashtra, India. This is a step to find if any of these indications can be re-evaluated to bring down the $\mathrm{C}$ section rate in the country to a level close to the standard set by WHO.

This study is aimed to find the rate of caesarean deliveries, various indications of the procedure and their relative contribution to associated maternal morbidity and mortality. So, we can analyse indications of caesarean section which can be reduced to lower the maternal and perinatal morbidity and mortality.

\section{METHODS}

This retrospective study was conducted over a period from January 2018 to May 2019 in the department of obstetrics and gynecology, N. K. P. Salve Institute of Medical Sciences and Research Centre and Lata
Mangeshkar Hospital, Hingna, Nagpur, Maharashtra, India. Data of patients who delivered by $\mathrm{C}$-section in our hospital during the defined study period were, studied and a statistically analysed. Records were obtained from the medical record section of our institute.

\section{Inclusion criteria}

- All women who underwent C-section (elective and emergency) at this institute during above mentioned period were included.

\section{Exclusion criteria}

- Women who delivered outside by C-section and referred to our institute post operatively for any further management and full-term normal delivery were excluded.

Various parameters like booked/unbooked cases, referral cases for C-section, indications of caesarean section, age, parity and gestational age of the women. Any associated maternal morbidity and mortality if any were noted.

The various categories of indications for caesarean sections included were repeat caesarean section, foetal distress, failed induction, arrest of labour, multiple gestation, mal- presentation, cephalopelvic disproportion (CPD), foetal indications (growth retarded foetus, big baby $>3.5 \mathrm{~kg}$ and prematurity), maternal indications (surgery like myomectomy, medical causes that could complicate during labour like heart disease and advanced age) and obstetrics indications (placenta previa abruption, placenta accrete, cord prolapsed, pre-eclampsia/ eclampsia) etc.

\section{Statistical analysis}

These data were entered in MS excel sheet. Accuracy and confidentiality were maintained. Descriptive statistics was used for analysis. Frequency and percentage were calculated.

One of the limitations in the present study is that we are not considering neonatal outcome and remote complications associated with C-sections.

\section{RESULTS}

The total number of women who delivered at our institute over the study period were 2811.Out of which total no. of women who underwent C-section were 1461 (51.97\%) and vaginal delivery were 1350 (48.03\%) (Table 1).

Table 1: Total number of deliveries.

\begin{tabular}{|lll|}
\hline Total deliveries & $\mathbf{2 8 1 1}$ & \\
\hline Vaginal & 1350 & $48.03 \%$ \\
\hline Caesarean section & 1461 & $51.97 \%$ \\
\hline
\end{tabular}


There were a total of 2811 deliveries during the study period, out of which, $1459(51.90 \%)$ had delivered via lower segment caesarean section (LSCS). The overall Csection rate was $51.97 \%$. The rate of primary $\mathrm{C}$-section was $939(64.27 \%)$, repeat C-section was 522 (35.72), elective C-section was 509 (34.83\%) and 952 (65.16\%) $\mathrm{C}$-section were done as emergency procedure. CPD, previous $\geq 2 \mathrm{C}$-section and malpresentation were the commonest indications for elective $\mathrm{C}$-section. Only 2 $(0.07 \%)$ women had classical C-section. The overall Csection rate was $51.97 \%$ (Table 2 ).

Table 2: The caesarean section rates.

\begin{tabular}{|lll|}
\hline Mode of delivery & No. of cases & $\%$ \\
\hline LSCS & 1459 & $51.90 \%$ \\
\hline Classical section & 2 & $0.07 \%$ \\
\hline Primary section & 939 & $64.27 \%$ \\
\hline Repeat sections & 522 & $35.72 \%$ \\
\hline Type of C-section & & \\
\hline Emergency CS & 952 & $65.16 \%$ \\
\hline Elective CS & 509 & $34.83 \%$ \\
\hline
\end{tabular}

Out of total $1461(51.97 \%)$ women, $138(9.44 \%)$ women were $<19$ years of age. $612(41.88 \%)$ women belonged to age group 20-25 years of age. $448(30.66 \%)$ women were in 26-30) years of age, 195 (13.34) women were 31-35 years of age and 68 (4.65) women were in $>35$ years of age group. Out of these $1461(51.97 \%)$ women, 901 $(61.67 \%)$ were primigravida, whereas 560 (38.32\%) were second or multi gravida. Result showed that only 982 $(67.21 \%)$ of women were booked for antenatal care (Table 3).

Table 3: Age and parity in women who underwent C-section.

\begin{tabular}{|lll|}
\hline Age group & No. of cases & $\%$ \\
\hline 19 year and below (teens) & 138 & $9.44 \%$ \\
\hline 20-25 years & 612 & $41.88 \%$ \\
\hline 26-30 years & 448 & $30.66 \%$ \\
\hline 31-35 years & 195 & $13.34 \%$ \\
\hline Above 35 years & 68 & $4.65 \%$ \\
\hline Parity & & \\
\hline Primipara & 901 & $61.67 \%$ \\
\hline Multipara (G2-G4) & 560 & $38.32 \%$ \\
\hline Grand multipara (G5+) & 0 & $0 \%$ \\
\hline Antenatal status & & \\
\hline Booked & 982 & $67.21 \%$ \\
\hline Unbooked & 479 & $32.78 \%$ \\
\hline
\end{tabular}

In $323(22.10 \%)$ C-section was done at $<37$ weeks. gestational age followed by $682(46.68 \%)$ C-section in $\geq$ 38 weeks of gestational age and $456(31.21 \%)$ C-section in $>40$ weeks of gestational age. $77.89 \%$ of the study group were term patients (Table 4).
Table 4: Percentage of $\mathrm{C}$-section in relation to period of gestation.

\begin{tabular}{|lll|}
\hline Period of gestation & No. of cases & $\%$ \\
\hline Preterm $(<37$ weeks $)$ & 323 & $22.10 \%$ \\
\hline Term $(\geq 37$ weeks) & 682 & $46.68 \%$ \\
\hline Post term $(\geq 40$ weeks) & 456 & $31.21 \%$ \\
\hline
\end{tabular}

Table 5: Indications of C-section.

\begin{tabular}{|lll|}
\hline Indications & No. of cases & $\%$ \\
\hline Prev. caesareans section & 522 & $35.72 \%$ \\
\hline Fetal distress & 206 & $14.09 \%$ \\
\hline Failure of induction & 189 & $12.93 \%$ \\
\hline Arrest of Labor & 116 & $7.93 \%$ \\
\hline PIH & 105 & $7.18 \%$ \\
\hline Oligohydramnios/IUGR & 95 & $6.50 \%$ \\
\hline Breech & 65 & $4.44 \%$ \\
\hline Refusal of vaginal birth & 62 & $4.24 \%$ \\
\hline CPD & 25 & $1.71 \%$ \\
\hline BOH & 21 & $1.43 \%$ \\
\hline Malpresentation & 19 & $1.30 \%$ \\
\hline Prematurity & 18 & $1.23 \%$ \\
\hline Multifetal gestation & 16 & $1.09 \%$ \\
\hline Total & 1459 & $100 \%$ \\
\hline
\end{tabular}

Among the indications, previous LSCS was the main indication consists of 522 women $(35.72 \%)$ followed by foetal distress in $206(14.09 \%)$ in women, failure of induction 189 (12.93\%), arrest of labour $116(7.93 \%)$ in women etc. and 2 classical C-section (0.07\%) in women (Table 5).

Table 6: Indications contributing to the repeat caesarean rate.

\begin{tabular}{|lll|}
\hline Indications & No. of cases & $\%$ \\
\hline Previous caesareans section & 206 & $39.66 \%$ \\
\hline Scar tenderness & 58 & $11.11 \%$ \\
\hline PIH & 56 & $10.72 \%$ \\
\hline Oligo hydramnios /IUGR & 54 & $10.34 \%$ \\
\hline Foetal distress & 38 & $7.27 \%$ \\
\hline Refusal of vaginal birth & 36 & $6.89 \%$ \\
\hline Breech & 21 & $4.02 \%$ \\
\hline BOH & 19 & $3.63 \%$ \\
\hline Malpresentation & 15 & $2.87 \%$ \\
\hline Prematurity & 12 & $2.29 \%$ \\
\hline Multifetal gestation & 7 & $1.34 \%$ \\
\hline Total & 522 & $100 \%$ \\
\hline
\end{tabular}

It was observed that commonest cause for the C-section in $206(39.66 \%)$ women was the previous C-section followed by scar tenderness in $58(11.11 \%)$ women, PIH in $56(10.72 \%)$ women, Oligohydramnios /IUGR in 54 $(10.34 \%)$ women, and foetal distress in 38 (7.27\%) women (Table 6). 
Table 7: Maternal morbidity and mortality.

\begin{tabular}{|lll|}
\hline Complications & No. of cases & $\%$ \\
\hline Wound infection & 64 & $4.38 \%$ \\
\hline Atonic PPH & 09 & $0.61 \%$ \\
\hline UTI & 57 & $3.90 \%$ \\
\hline Gaped wound & 76 & $5.20 \%$ \\
\hline Total & $206 / 1461$ & $14.09 \%$ \\
\hline
\end{tabular}

The caesarean sections were associated with increased risk of maternal and perinatal morbidity as compared to vaginal deliveries even in low risk cases. In present study Out of 1461 women 206 (14.09\%) women had various complications mainly, gaped wound 76 (5.20\%), wound infection $64(4.38 \%)$, UTI $57(3.90 \%)$, atonic PPH in 09 $(0.61 \%)$ women and $2(0.07 \%)$ had classical C-section. There was no maternal mortality during this period (Table 7).

\section{DISCUSSION}

In this study the total number of deliveries was 2811 and of which $1461(51.97 \%)$ was caesarean deliveries. Increased caesarean rate is a major health concern worldwide.
There has been a steady increase in the rates of C-section in both developed and developing countries. The reasons for the increased caesarean are multifaceted. Commonly cited causes are, ${ }^{2,10,11}$

- Avoiding difficult manipulative or instrumental vaginal deliveries

- Foetal distress detected especially with the use continuous electronic foetal monitoring

- Liberal use of caesarean in high risk cases like Breech presentation, previous caesarean delivery, growth retarded foetus, multiple pregnancy, preterm baby

- Improved safety of C-section with better surgical techniques, anaesthesia, better availability of blood and its products, advanced antibiotics

- Busy schedule of the obstetrician specially those working in private sector and also an apprehension of the obstetrician regarding the fear of poor neonatal outcome

- Increased incidence of IVF and other high-risk pregnancy

- Increased institutional deliveries because of awareness in people

- Fear of the patient for labour pain.

Table 8: Caesarean section rates in other studies.

\begin{tabular}{|llll|}
\hline Study & Place & Study period & CSR\% \\
\hline Present study & LMH, Nagpur, Maharashtra & January 2018-May 2019 & $51.97 \%$ \\
\hline Subudhi KT et al & Bhubaneswar, Odisha & May 2017-April 2018 & $35.45 \%$ \\
\hline Gupta M et al & Jaipur, Rajasthan & January 2016-December 2016 & $32.46 \%$ \\
\hline Singh G et al & Agroha, Haryana & January 2012-December 2012 & $51.1 \%$ \\
\hline Subhashini R et al & Visakhapatnam, Andhra Pradesh & January 2014-December 2014 & $25.66 \%$ \\
\hline Yadav RG & Vadodara, Gujarat & January 2013-December 2013 & $28.87 \%$ \\
\hline Manjulatha B et al & Tirupati, Andhra Pradesh & January 2012-December 2012 & $22.20 \%$ \\
\hline Shiba M et al & Mumbai, Maharashtra & January 2011-December 2011 & $28.93 \%$ \\
\hline Samdal LJ at al & Rural Nepal & August 2014-August 2015 & $9.50 \%$ \\
\hline Jawa A et al & Jaipur, Rajasthan & December 2015-May 2016 & $31.80 \%$ \\
\hline Preetkamal et al & Vallah, Amritsar, Punjab & May 2015-April 2016 & $33.20 \%$ \\
\hline Yadav S et al. & Mullana, Ambala, Haryana & Apr 2015-March 2016 & $21.60 \%$ \\
\hline Saxena N et al & Dehradun, Uttarakhand. & January 2015-December 2015 & $31.40 \%$ \\
\hline Sarma P et al & Sonitpur, Assam & January 2015-December 2015 & $27.60 \%$ \\
\hline Chavda D at al & Rajkot, Gujarat & January 2015-September 2015 & $19.90 \%$ \\
\hline Nikhil A et al & Sola, Gujarat & June 2013-December 2013 & $25.18 \%$ \\
\hline Bade P et al & Latur, Maharashtra & March 2013-August 2013 & $23.97 \%$ \\
\hline Padmaleela K et al & Andhra Pradesh & April 2011-March 2012 & $31.00 \%$ \\
\hline Liu et al & Mainland China, multicenter & January 2011-December 2011 & $54.90 \%$ \\
\hline Santhanalakshmi C et al & Maduranthagam, Tamil Nadu & January 2011-December 2014 & $12.5 \%$ \\
\hline Bhasin SK at al & East Delhi, India & September 2003-May 2004 & $34.40 \%$ \\
\hline Kambo I et al & 30 medical colleges/teaching hospitals in India & 1998-1999 & $25.40 \%$ \\
\hline
\end{tabular}

In this study the rate of caesarean section observed is $51.90 \%$, which is almost $>3$ times the accepted upper norm of WHO i.e. $15 \% .^{11}$
The cause for which may be as the present study is conducted in a tertiary care hospital and medical college which is situated at rural area of Nagpur City, 
Maharashtra. As such, most of the cases attending the OPD and also those availing the emergency services are basically referred cases from the nearby and also some of the distant primary health centre (PHC), community health centre (CHC), sub divisional dispensaries, private hospitals and even some cases from other district and state. A team of obstetricians, anesthesiologists, and neonatologists are available round the clock for managing emergencies with well-equipped setup.

Among the indications, previous LSCS was the main indication consists of 522 women $(35.72 \%)$ followed by foetal distress in $206(14.09 \%)$ in women, failure of induction $189(12.93 \%)$, arrest of labour $116(7.93 \%)$ in women etc. and 2 classical C-section $(0.07 \%)$ in women.

In the present study, the most common indication was previous caesarean section $522(35.72 \%)$. Similar results were found in studies conducted by Liu et al, G Singh et al, Jawa A et al, Chavda D et al, Nikhil A et al, Prashant Bade et al and Osman BALCI et al (Table 8). 2,12,13
Practice of trial for vaginal birth after caesarean (VBAC) is less in study hospital due to doubtful scar strength, details regarding previous $\mathrm{C}$-section being not available, more no. of deliveries being conducted in the institution and more no. of referrals in late stage of labour. No trial was given to patients with previous 2 or more sections, those who presented with scar tenderness, dealing with high risk pregnancy as having IVF unit, in those previous women who refused for vaginal delivery. ${ }^{2,12}$ The second common indication in the present study was foetal distress $206(14.09 \%)$.

Failure of induction accounted for 189 (12.93\%); arrest of labour $116 \quad(7.93 \%)$ Breech-65 (4.44\%); oligohydramnios/IUGR-95 (6.50\%); PIH accounted for $105(7.18 \%)$. Rest in decreasing order were multifetal gestation, prematurity, obstructed labour, $\mathrm{BOH}$, malpresentation, CPD.

The indications of caesarean section in the present study can be compared with the following studies (Table 9)..$^{7,12,13}$

Table 9: The caesarean section indications.

\begin{tabular}{|llllllllll|}
\hline Indications & $\begin{array}{l}\text { Present } \\
\text { study }\end{array}$ & $\begin{array}{l}\text { Das RK } \\
\text { et al }\end{array}$ & $\begin{array}{l}\text { Sarna } \\
\text { P et al }\end{array}$ & $\begin{array}{l}\text { Jawa A } \\
\text { et al }\end{array}$ & $\begin{array}{l}\text { Chavda } \\
\text { D et al }\end{array}$ & $\begin{array}{l}\text { Bade P } \\
\text { et al }\end{array}$ & $\begin{array}{l}\text { Nikhil } \\
\text { A et al }\end{array}$ & $\begin{array}{l}\text { Balci O } \\
\text { et al }\end{array}$ & $\begin{array}{l}\text { Singh } \\
\text { G et al }\end{array}$ \\
\hline Previous C-section & $35.72 \%$ & $29.96 \%$ & $23.00 \%$ & $23.90 \%$ & $39.90 \%$ & $24.80 \%$ & $42.09 \%$ & $36.77 \%$ & $29.70 \%$ \\
\hline Arrest of labour & $7.93 \%$ & $13.93 \%$ & $2.02 \%$ & $5.93 \%$ & $4.80 \%$ & $17.60 \%$ & $6.32 \%$ & $9.88 \%$ & $5.10 \%$ \\
\hline CPD & $1.71 \%$ & $11.84 \%$ & $30.99 \%$ & $16.06 \%$ & $19.10 \%$ & $11.70 \%$ & $10.94 \%$ & $13.17 \%$ & $12.1 \%$ \\
\hline Fetal distress & $14.09 \%$ & $10.97 \%$ & $2.99 \%$ & $13.00 \%$ & $0.90 \%$ & $16.60 \%$ & $10.94 \%$ & - & $25.40 \%$ \\
\hline Breech/malpresentation & $5.74 \%$ & $6.08 \%$ & $3.03 \%$ & $9.37 \%$ & $18.6 \%$ & $6.80 \%$ & $8.26 \%$ & $5.48 \%$ & $11.3 \%$ \\
\hline Oligohydroamnios/IUGR & $6.5 \%$ & $5.21 \%$ & $5.00 \%$ & $5.93 \%$ & $2.00 \%$ & $4.00 \%$ & $3.89 \%$ & - & - \\
\hline Failed induction & $12.93 \%$ & $5.21 \%$ & $14.00 \%$ & - & $7.30 \%$ & $2.90 \%$ & - & $3.11 \%$ & - \\
\hline PIH & $7.18 \%$ & $4.87 \%$ & $12.99 \%$ & $11.66 \%$ & - & - & $1.94 \%$ & $4.20 \%$ & $4.80 \%$ \\
\hline Prematurity & $1.23 \%$ & - & - & - & - & - & - & - & - \\
\hline Multifetal gestation & $1.09 \%$ & - & - & - & - & - & - & - & - \\
\hline
\end{tabular}

The caesarean sections were associated with increased risk of maternal and perinatal morbidity as compared to vaginal deliveries even in low risk cases. In our study, the morbidity rate was found as $206(14.09 \%)$. Gaped wound $76(5.20 \%)$ was the commonest complication followed by wound infection 64 (4.38\%), UTI 57 (3.90\%) and Atonic PPH in $09(0.61 \%)$ women and some women had post op fever and spinal headache. These complications occur especially in emergency cases. Similar results were found in a study by Lakshmi $\mathrm{C}$ et al the commonest complication was wound infection (38\%). The next common complications were UTI, post op fever and spinal headache, $20 \%, 19 \%$, and $14.4 \%$ respectively. ${ }^{7,13}$ Similar results were found in a study by Osman BALCI et al the morbidity rate was found as $14 \%$. Febrile morbidity was detected $11 \%$ with postoperative endometritis, urinary tract and wound infection rates were detected $1.28 \%, 1.09 \%$ and $0.73 \%$ respectively. ${ }^{2,14}$ In this study most common morbidity was gaped wound $(5.20 \%)$, wound infection $(4.38 \%)$ and UTI (3.90\%) etc.

\section{CONCLUSION}

A high rate of caesarean deliveries was observed. Individualisation of the indication and careful evaluation, following standardized guidelines can help us to limit Csection. This may be due to being a tertiary care centre, women referred to us from nearby areas as they are not performing $\mathrm{C}$-section in their setup in woman with high risk pregnancy. Previous caesarean section was the leading indication in our study which is worrisome. In conclusion it would be ideal to initiate obstetric audits by intradepartmental meetings, to assess the management of labour and indications of caesarean section in influencing outcome. Use of standardized management guidelines and practice will be helpful.

\section{ACKNOWLEDGMENTS}

Authors would like to thank Dr. S. Joshi, Head of the Department for her valuable guidance and support. 
Authors would like to acknowledge the medical records department of study institution for allowing us to access the in-patient record files.

Funding: No funding sources

Conflict of interest: None declared

Ethical approval: The study was approved by the Institutional Ethics Committee

\section{REFERENCES}

1. Bala S, Patidar BL, Gupta B. A retrospective analysis of annual caesarean section rate in a tertiary care hospital, Kota. J Med Sci Clin Res. 2017;5(07):25325-9.

2. Gupta M, Garg V. The rate and indications of caesarean section in a tertiary care hospital at Jaipur, India. Int J Reprod. Contracept Obstetric Gynecol. 2017;6(5):1786-92.

3. National Institutes of Health state-of-the-science conference statement. Caesarean deliver on maternal request. Obstetric Gynecol. 2006;107:1386-97.

4. Sethi N, Sharma SP. Rising trends of caesarean section: a retrospective study. India Int $\mathrm{J}$ Reprod Contracept Obstet Gynecol. 2019;8(4):1548-52.

5. FOGSI-Caesarean Rates (JDT). Available at: https://www.fogsi.org/fogsi-cesarean-rates-jdt/. Accessed on $10^{\text {th }}$ February 2020.

6. Gupta M, Garg V. The rate and indications of caesarean section in a tertiary care hospital at Jaipur, India. Int J Reprod Contracept Obstet Gynecol. 2017;6(5):1786-92.

7. Das RK, Subudhi KT, Mohanty RK. The rate and indication of caesarean section in a tertiary care teaching hospital eastern India. Inter J Contemp Pediatr. 2018;5(5):1733-9.

8. Patnaik M, Das B. Retrospective observational study of caesarean section cases in a tertiary care hospital in Odisha. Indian $\mathbf{J}$ Obstet Gynecol Res. 2017;4(2):112-5.

9. Singh, Kumar P. Rising caesarean births: a growing concern, Indian Council of Medical Research, Economic Political Weekly. 2018;53:22-4.

10. Manjulatha B, Sravanthi TP. Caesarean section rates in a Teaching Hospital: a ten-year review. IOSR J Dent Med Sci. 2015:14(8):1-5.

11. WHO Statement on caesarean section rates, 2015, WHO reference number: WHO/RHR/15.02. Available at http://www.who.int/reproductivehealth/ publications/ maternal_ perinatal_ _health/csstatement/en/. Accessed on $10^{\text {th }}$ February 2020.

12. Singh G, Gupta ED. Rising incidence of caesarean section in rural area in Haryana India: A retrospective analysis. Internet $\mathrm{J}$ Gynecol Obstetr. 2013;17(2):1-5.

13. Santhanalakshmi C, Vijayalakshmi Gnanasekaran DA. A retrospective analysis of cesarean section in a tertiary care hospital. Sepsis. 2013;5(9.3):4.

14. Balcı O, Gezginç K, Acar A. The outcome analysis of cesarean section cases in one-year period. Gynecol Obstet Reprod Med. 2007;13(1):26-8.

Cite this article as: Kose V, Sadhvi K. Study of caesarean section at tertiary care centre: a retrospective study. Int J Reprod Contracept Obstet Gynecol 2020;9:2138-43. 